See discussions, stats, and author profiles for this publication at: https://www.researchgate.net/publication/301913235

\title{
Students' engagement in Distance Learning: Creating a scenario with LMS and Social Network aggregation
}

Conference Paper · November 2015

DOI: 10.1109/SIIE.2015.7451646

CITATIONS

5

3 authors:

ISCTE-Instituto Universitário de Lisboa

13 PUBLICATIONS 45 CITATIONS

SEE PROFILE

Maria Potes Barbas

Universidade Aberta

15 PUBLICATIONS 43 CITATIONS

SEE PROFILE

Some of the authors of this publication are also working on these related projects:

Uptake_ICT2life-cycle: digital literacy and inclusion to learners with disadvantaged background View project

Competências Digitais View project
READS

445

Lina Morgado

Universidade Aberta

63 PUBLICATIONS 216 CITATIONS

SEE PROFILE 


\section{Students' engagement in distance learning: creating a scenario with LMS and Social Network aggregation}

\author{
Inês Messias \\ LE@D- Laboratório de Educação a \\ Distância e Elearning, \\ Universidade Aberta, Portugal \\ ines.messias@gmail.com
}

\author{
Lina Morgado \\ LE@D -Laboratório de Educação a \\ Distância e Elearning \\ Universidade Aberta, Portugal \\ lina.morgado@uab.pt
}

\author{
Maria Barbas \\ ESE Santarém, Instituto Politécnico \\ Santarém, Portugal \\ mariapbarbas@gmail.com
}

\begin{abstract}
Already a part of our daily lives, Web 2.0 is becoming also a part of Education, as it evolves to accompany society, education is becoming more personal, and with a focus on knowledge, reflection, social connection and engagement, as to include both digital natives and immigrants [1]. According to Siemens [2] today's learning depends on connectivity among individuals and it tends to dissolve frontiers between formal and informal learning. This paper presents a study ${ }^{1}$, that aims to comprehend how an informal platform (such as Facebook) while complement of a formal platform (such as Moodle) can contribute to a greater engagement by the Higher Education level students', as well as to measure the impact these tools can have on the knowledge acquisition process. Embedded on the Higher Education context, the study is centred in the levels of the students' engagement and on the frequency and quality of their contributions in Forums, being its participants, lecturers and students of this level of education. Since it is objective of the study to understand how interaction and collaboration contribute to students' involvement in elearning hybrid contexts the adopted theoretical framework is the Activity Theory, and the methodological approach chosen is of a mixed nature, using Social Network Analysis tools (SNA).
\end{abstract}

Keywords-Web 2.0; Facebook; Moodle; engagement; collaboration; distance learning.

\section{INTRODUCTION}

This study aims to comprehend how a formal LMS (Learning Management System), such as Moodle, when associated with an online social network such as Facebook can contribute to influence the students' engagement in their learning process. To measure this, was necessary to first list the common characteristics of these two environments, by defining both, and to also define what is understood by engagement and collaboration.

According to Oncu \& Cakir [3] "Learner engagement is defined as the effort learners devote to activities that are

${ }^{1}$ Initial phase of the investigation framed on a doctoral program, specializing in Distance Education and eLearning (eDeL) at the Universidade Aberta. focused on education." While for Anderson [4] "engagement is developed through interaction." As for Chickering \& Gamson [5] they state that among other factors this is centered on the student's interaction, i.e. "learner interaction in online learning environments has implications on learner engagement and collaboration." Whit this in mind this study will focus on analyzing the frequency of interaction among the participants in the study, so to verify the level of interaction among students in both platforms.

As for collaboration, several authors associate online collaboration with the quality of students' contributes. For Valle et al. [6], Hiltz et al. [7] and Khan [8] collaboration can be measured by the "improvement in volume and quality of student involvement, satisfaction, engagement, and higherorder learning". Moreover, group discussions in online learning environments through collaborative involvement increase not only the productivity of the group but also individuals' ability to think critically [9] [10].

Hence, this study's questions are:

1- How can Facebook, when used as a complement for Moodle, contribute to students' higher engagement in their learning in Higher Education?

2- How can engagement and collaboration be measured in these platforms?

These questions take us to the goals of this study:

To know the level of engagement, the quality of interaction and collaboration, to help define strategies to not only reduce the number of students' dropouts in e-learning contexts, as to contribute to a greater quality of learning. Another consequence can be increasing students' satisfaction. As such this study can make impact in other institutions that have adopted or aim to adopt these tools in their teaching activities.

In order to first implement the study, it will be necessary to know the students' and the teachers' profile, in order to contextualize the study environment. Having this into consideration the main goal of this study is: To understand the 
relevance of Web 2.0 tools to engagement and to quality of learning in e-learning contexts.

This goal can be subdivided into more specific goals, in order to analyze students' engagement in both platforms:

1- To know the profiles or the students and teachers involved in this study;

2- To gather data of the frequency and quality of interactions between the study's participants, in the groups/forums of both tools;

3- To gather data about the students' quality of contributions in forums/groups of both tools;

4- To analyze the gathered data.

\section{TODAY'S STUDENT PROFILE}

In order to best understand what students aim form with their studies and how they learn it is necessary to first set out their characteristics. According to several authors today's students have grown surrounded by digital technology and are used to utilize several tools simultaneously, being regarded as multitaskers. Some consider them as being digitally-savvy, by using any kind of device almost intuitively. But what are the specific characteristics of the students of nowadays? Some authors present specific terms for the different generations of students. Some older terms, other more current, describing a generation increasingly more linked to digital. Jones and Shao [11] list some of the most referenced terms such as "Millennials", used by Howe and Strauss [12] [13] [14], "Net generation", defended by Tapscott [15] [16] and Oblinger \& Oblinger [17] the terms "Digital Natives / Digital Immigrants" used by Presnky [1] [18] [19] and Palfrey and Gasser [20], the term Generation Y, described by Jorgensen [21], Weiler [22] and McCrindle [23]; The term IM Generation used by Lenhart, Rainie and Lewis [24], the term "Gamer generation", described by Carstens and Beck [25] and "Homo Zappiens" defended by Veen [26]. Jones and Shao [11] note that each of the terms presented by these authors differ depending on the social context in which they are involved, but appear to have similar terms between them. As for the most current terms the author refers to two generations: the "Google generation" with the term assigned by Rowlands et al. [27] and the i-Generation, identified by Rosen [28].

For this study it is important to understand if today's Portuguese students have the same characteristics proposed by these international authors, or if there is the need to adapt some of the characteristics and, hence, the teaching and learning strategies. As such, it was done first a gathering of all the terms mentioned above, that will later on be tested under the form of a questionnaire that the students involved in the study must answer to. But first, it is important to present the characteristics of the two more recent mentioned terms: the Google Generation and the i-generation.

The definition of "i-generation" attributed by Rosen [28] is more specific, since the " $i$ " is due to the wide use students make of iPods, iTunes, Wii, iChat, iHome and iPhone. The author suggests that this term can be applied to those born after 1990, however, in Portugal, the widespread use of these devices only occurs after the year 2000. Thus, for this study, we can only consider i-genners as those born after 2000 and these are only expected to start arriving to universities in about 4 or 5 years (2020), being important for teachers to start preparing for these students.

As such it is important to know the learning profile of these students. I-Generation is described by Rosen [28] as having grown up with digital technology literally since they were born, being the center of their lives. They are constantly connected, always reachable, do multitasking, and social interaction online, where they create and share content. They learn best by touch, move, do and experience, need constant motivation and have strong family ties. They are confident, open to change, are used to collective reflection and instant gratification.

Also according to Rosen [28] each of us can fall into one generation, provided the context and environment in which we grow. The author suggests a chronological order: 1) Baby Boomers (1946-1964); 2) Generation X (1965-1979); 3) Generation Net (1980-1989); 4) i Generation (after 1990). And though the author delimit the i-Geners as to all born after 1990, in Portugal, by this time, the circumstances presented by the author, have not yet verified. In fact, only for the last 10 years or less, it can be said that the Portuguese young people live in this context, with the means to acquire the features that are part of the i Generation. Thus, we propose the following timeline, slightly modified:

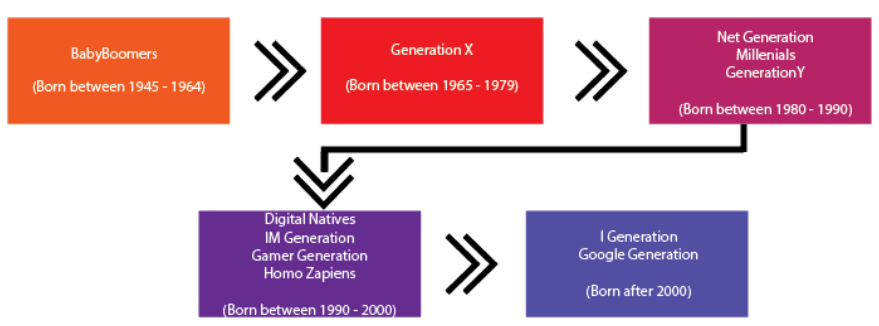

Fig. 1. Proposed chronological order for students profiles

While no one completely belongs to a specific generation and may show mixed features, and although these terms and characteristics can be applied to a particular time interval, this may be different depending on the country's development level, even the family financial capacity can influence.

Although in the previous schematic the Google generation is placed to those born after 2000, this is the proposed timeline of the study, adapted to the Portuguese reality. As for Rowlands et al. [27], it is propose that all born after 1993 can fit the profile, has it gathers all that have born surrounded by internet. Although initially this description is very simplistic, the authors consider some features for this profile. They believe those belonging to the Google-Gen to feel more comfortable with a computer with a pen and paper, or use the search engines, like Google, to do research instead of more secure means where they can be sure of the validity of the content. They state that these young people prefer quick searches to the slower but more effective research when it comes validity, concluding that students are not able to assess the relevance of the results of research they do, and 
consequently, the contents absorbed by them are most of the time show as superficial.

Other authors such as Johnson et al. [29] [30] [31] refer to the fact that students already spend much of their time on the Internet, not only socialize but learn, exchange ideas and new information, and believe that the institutions should take this into account and bring the web 2.0 for their teaching practices, not only because the students here are comfortable, but because it can motivate them and provide new skills, either at the digital level as at the level of cooperation, collaboration and reflection. They believe that students today have digital culture, i.e., know how to use a large number of basic web tools for their day-today tasks, but note that to use these same tools for the acquisition and creation of knowledge students need to know how to reflect and learn how to adapt knowledge in an innovative way. These skills should be given by teachers, requiring the latter to master all the necessary skills to then teach the students. These authors believe that Web 2.0 learning when applied correctly can lead students to collaborative work, to the debate of ideas and the construction of knowledge in cooperation. “(...) emerging digital tools make it easier for students to ask and respond to each other's questions and for instructions to provide feedback in real-time. " [29]

\section{FORMAL LEARNING ENVIRONMENTS - LMS MOODLE}

Noticing the continuous increase in the usage of technology academics have started to change the teacher-centered paradigm to a more student-centered one, adopting formal online closed platforms, where students and teachers can interact in a formal online environment. Learning Management Systems (LMS) offer a set of tools that give the teacher the opportunity to create and manage online courses. Among several LMS, the most used are: Moodle, BlackBoard, Toobook, WebCT. Moodle is of the above mentioned the most used, probably because it is an open source environment, which reduces financial costs with platform acquisition and maintenance. [32]

Moodle (Modular Object-Oriented Dynamic Learning Environment) was developed by a $\mathrm{PhD}$ student in 1999 and opened to the public in 2001. According to Moodle's online page the goal of this project is to allow educators to manage and promote learning. It's an online open source platform, integrating a set of tools that allow to create and manage a space where students can access content made available by teachers allowing synchronous and/or asynchronous communication among users. According to Alves and Gomes the specific features of Moodle meet in four dimensions:

- Protected access and management of user's profiles create a private web environment for participants, allowing to assign different levels of permissions for teachers and students;

- Managing access to content, enabling the teacher to make available online content in various formats, manage the time students have access to it and even control how students interact with it;

- It has tools for synchronous and asynchronous communication, allows communication between users;
- Allows activities control and keeps record of all activities and actions made by students and teachers.

Moodle allows three user levels: The administrator role, the teacher and the student. They all have different permissions: Administrator can manage the whole environment, the teacher can manage events, courses and subjects within areas previously defined by the administrator, and the student can access and interact in events to which he subscribed. Apart from the above mentioned features, Moodle has a simple interface, divided by modules, allowing a rapid learning curve regarding its use. [33]

However, some negative aspects have been noticed in studies developed on this platform, including privacy issues, relating to questions on forums, because every time a student makes a contribution to a forum an email is sent to all users who participate in it, leading to some students, feel inhibited to ask questions or comments, as much as would be desired. [34]

Wood [33] also noted that some of the students have never had or do not have continuous contact with a computer. This same author reported that only a minority of students today are actually digitally savvy, having demonstrated some difficulties when integrating on platforms with which they are not acclimatized.

\section{FACEBOOK AS AN INFORMAL LEARNING PLATFORM}

Learning in the digital age depends not only on individual acquisition, storage or knowledge collection. According to Siemens [2] today's learning depends on connectivity. It is necessary that students acquire certain skills that help them create knowledge networks, using of Web 2.0 tools professionally, even the tools that many of us only see it as entertainment. In a society that calls itself digital, know how to use all the tools that are available effectively is a necessity, especially for the student who frequents Distance Learning. For this student, the isolation can be an obstacle, when eliminating the chance of creating informal knowledge with study groups and colleagues.

According to Forbes, in December 2013, Facebook remains the social network with most users. "Facebook continues to lead the pack in terms of number of active monthly users (15.1 billion at last count)." [35]

In view of these data, we highlight Facebook between social networks, as a possible platform to be used in distance education, seeking to understand what Facebook's features are and what role it may have for learning in distance education.

To feel that one belongs to a community is identified in several studies as an essential aspect for students to be motivated. According to Madge et al. [36] socialization was one of the most significant contributions that Facebook has brought to the university students. In their study it is mentioned that $84 \%$ say they use this network every day and $68 \%$ say they feel part of the Facebook community. The feeling of belonging to a community helps not only the integration of students as facilitates communication between those who belong to it. For distance education students this may be a positive feature for the adoption of Facebook in school context, while it can 
facilitate communication among peers and between students and teachers, integrating the student and keeping close contact, thus making them feel part of the community.

According to Nentwich and Konig [37] Facebook demonstrates potential as a platform for public relations for scientists, universities, institutes and school associations. The same authors report that platforms like Facebook can be used for synchronous communication with specific reference to the contribution that they could bring elearning. By creating a network of contacts relevant to the areas of interest, you can use Facebook not only as a means of communication but for cooperation and motivation.

\section{A. The required skills and educative potential}

According to Bassani [38] online learning has had different terminologies, such as e-learning, Web-based learning, distance learning, although all refer to the use of the Internet to access and interact with online content, with the teacher and other students, in order to obtain support during the learning process and thus gain knowledge, to construct personal meaning and grow professionally with the learning experience. All these features can only be enhanced by social networks like Facebook.

But why suggest the use of Facebook instead of other social network more dedicated to research? Professional social networks are not attractive to most students, unlike Facebook, which is part of their daily routines. "Research has suggested that Facebook is a potentially useful tool for promoting effective academic practice" [36] And although the creation of a network with educational and scientific relevance can take time, although its benefits are not able to glance at short term, Nentwich and Konig [37] state that for the success of educational investment in this network, skepticism must be exceeded. An initial step might be to create groups of closed access for students of a specific course or chair, where only students belonging to the same institution or class can enter.

Social networks such as Facebook have the potential to increase the frequency and diversity of collaborative works between students and even among teachers and researchers. Particularly for Distance Learning, where one of the problems is the isolation of students, sometimes leading to academic abandonment, these networks may contribute positively due to their social side and as they allow frequent and close contact with either colleagues or teachers, but also experts, creating the feeling of belonging to a community and enhancing integration, at the same time it enhances sharing and collaboration.

According to Burke et al. [39] the success of discussion groups in a community depends on motivating participation, generated by a group with several participants, where the quantity and quality of contributions tend to grow with the motivation of participants. Belonging to a community that does not show itself enclosed on formal platforms but that is dynamic and open to the world and to collaboration as well as the social networks to which students already call theirs, may bring the necessary motivation to the higher distance education student, not only to remain enrolled but also to excel in its studies. "A small-scale survey [40] found that students who experienced more instructor self-disclosure on Facebook reported more motivation and higher levels of learning. " [41]

\section{THEORETICAL FRAME OF THE STUDY - ACTIVITY THEORY}

Being object of this study to comprehend in what way interaction and collaboration contribute to the students' engagement in hybrid e-learning contexts, the chosen theoretical frame is the Activity Theory, because its fundamental components are interaction and relationship between the subject and the object of study.

Activity Theory is considered by several researchers as facilitator and effective for studies about engagement and collaboration between students. According to Collins et al. [42] and Christine (2002) "activity theory helps achieve efficiency and quality in the research by helping directly transfer the data into the artefacts and relationships in the model. Moreover, they state that the given artefacts and the relationships are enough to explain the major aspects of the activity under investigation. " [3]

Created by Engestrom [43] this theory establishes a schematic (Fig. 2) that helps to describe how people participate in activities, giving the researcher the opportunity to make a profound analysis of the used tools, the bond that is established between the users and between the study's goal and consequences.

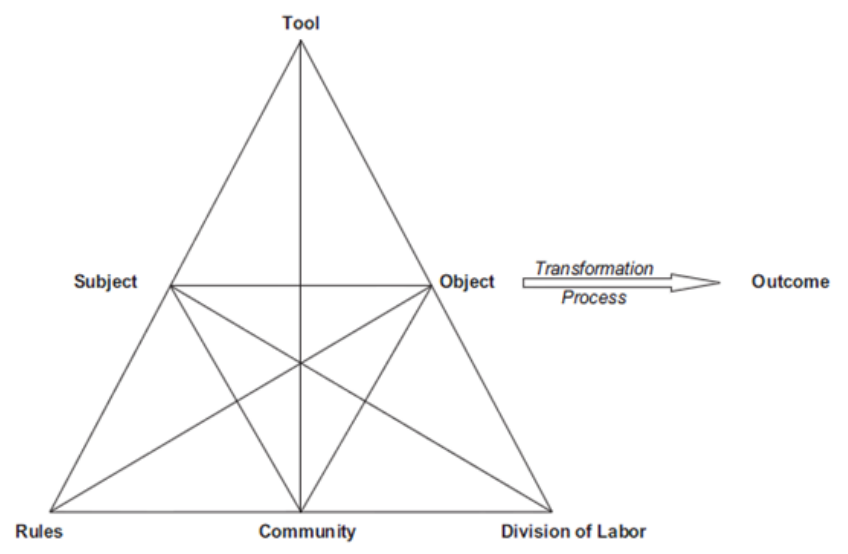

Fig. 1 Activity Theory squematics

Using the schematics proposed by Engestrom, in this study the subjects will be the participants (students and teachers), the tools will be the ones used to succeed in achieving the goal of the study i.e. Moodle and Facebook), the object is the reason that makes people use these tools, the purpose that makes students and teachers use them. And these are the 3 main elements of this theory. After the project is implemented will we have the outcome, what resulted of this study. The rules are the good practice norms for the use of the tools to be tested, and the teachers involved on the study will establish what rules they use for their teaching strategies when applying the tools. The community consists on the environment where the subjects are, in this case, a Higher Education Institution. The division of labor is the role each individual will have in these study. 


\section{METHODOLOGICAL DESIGN FUNDAMENTALS}

The research nature of this study is mixed, due to the need of gathering both qualitative and quantitative data, using different techniques to gather and analyze them.

The qualitative data will be gathered from the students' posts in Moodle discussion forums and in Facebook groups, and from the open questions students will answer in the initial and final questionnaires. They will then be analyzed with WebQDA. The quantitative data will the gathered using learning analytics tools, such as SNAPP and Gephi, and also from some questions in the initial and final questionnaires.

As a methodology this study will use Social Network Analysis (SNA), in order to analyze the students' group dynamics in both tools. SNA is an interdisciplinary methodology developed by social psychology researchers in the 60 and 70 decades, while working in collaboration with researchers in mathematics, computers and statistics. In the 90 decades Wasserman \& Faust described it as the analysis of relationship patterns between individuals and the exchange of resources during those relationships [44] More recently in 2004, Freeman [45] describes it as having 4 proprieties: "(1) It involves the intuition that links among social actors are important. (2) It is based on the collection and analysis of data that record social relations that link actors. (3) It draws heavily on graphic imagery to reveal and display the patterning of those links. And (4) it develops mathematical and computational models to describe and explain those patterns." [45]

SNA differs from other methodologies because it incorporates different levels of analysis. It can measure at group, local or network level, the decision on the appropriate measure depends on the study and on what the researcher wants to show.

\section{REFERENCES}

[1] M. Prensky, "Digital Natives, Digital Immigrants, Part II: Do They Really Think Differently?," Horizon, NCB Univ. Press, vol. 9, no. 6, 2001.

[2] G. Siemens, "elearnspace. Connectivism: A Learning Theory for the Digital Age," Elearnspace, 2004. [Online]. Available: http://www.elearnspace.org/Articles/connectivism.htm. [Accessed: 12-Apr-2014].

[3] S. Oncu and H. Cakir, "Research in online learning environments: Priorities and methodologies," Comput. Educ., vol. 57, no. 1, pp. 1098-1108, Aug. 2011.

[4] T. Anderson, "Modes of interaction in distance education: Recent developments and research questions," in Handbook of Distance Education, 2003, pp. 129-144.

[5] A. W. Chickering and Z. F. Gamson, "Seven Principles For Good Practice in Undergraduate Education," Washington Center News, 1987.

[6] R. del Valle, S. Öncü, N. F. Koksal, N. Kim, P. Alford, and T. M. Duffy, "Effects of Online Cognitive Facilitation on Student Learning," Academia.edu, 2007.
S. R. Hiltz, N. Coppola, N. Rotter, M. Turoff, and R. Benbunanfich, "Measuring the Importance of Collaborative Learning for the Effectiveness of ALN : A Multi-Measure, Multi-Method Approach," Sloan Consort., vol. Volume 4, no. Issue 2, pp. 103 $125,2000$.

[8] B. H. Khan, "The Global E-Learning Framework," in Stride Handbook - E-learning, 2009, pp. 42-51.

[9] C. Angeli, N. Valanides, and C. J. Bonk, "the quality of computermediated interactions," Br. J. Educ. Technol., vol. 34, no. 1, pp. 3143,2003

[10] D. R. Garrison, T. Anderson, and W. Archer, "Critical thinking, cognitive presence, and computer conferencing in distance education," Am. J. Distance Educ., vol. 15, no. 1, pp. 7-23, Jan. 2001

[11] C. Jones and B. Shao, "The Net Generation and Digital Natives: Implications for Higher Education," 2011.

[12] W. Strauss and N. Howe, Generations: The History of America's Future, 1584 to 2069. New York: William Morrow and Company, 1991.

[13] N. Howe and W. Strauss, Millennials Rising: The Next Great Generation. New York: Vintage Books, 2000.

[14] W. Strauss and N. Howe, Millennials Go to College: Strategies for a New Generation on Campus, 2nd ed. New York: American Association of Collegiate Registrars, 2003.

[15] D. Tapscott, Growing Up Digital by Don Tapscott. McGraw-Hil Inc.,US (1 Oct. 1997), 1998

[16] D. Tapscott, "Characteristics if a Generation: The Eight Net Gen Norms," in Grown Up Digital: how the net Generation is changing your world, McGraw-Hill, 2009, pp. 73-96.

[17] D. Oblinger, J. Oblinger, G. Roberts, B. McNeely, C. Windham, J. Hartman, P. Moskal, C. Dziuban, R. Kvavik, J. Ramaley, L. Zia, A. Clayton-Pedersen, J. Wager, A. Moore, J. Moore, S. Fowler, M. Brown, J. Lippincott, C. Barone, and C. Dede, Educating the net generation: A Handbook of findings for practice and policy. Educause, 2005.

[18] M. Prensky, "H.Sapiens Digital: From Digital Immigrants and Digital Natives to Digital Wisdom," Innovate, 2009.

[19] M. Prensky, "From Digital Natives to Digital Wisdom," in From Digital Natives to Digital Wisdom: Hopeful Essays for 21 st Century Education, California: Corwin - A SAGE company, 2012.

[20] J. Palfrey and U. Gasser, Born Digital: Understanding the First Generation of Digital Natives. New York: Basic Books, 2008.

[21] B. Jorgensen, "Baby Boomers, Generation X, and Generation Y: Policy Implications for Defence Forces in the Modern Era," Foresight, vol. 5, no. 4, 2003.

[22] A. Weiler, "Information-Seeking Behavior in Generation Y Students: Motivation, Critical Thinking, and Learning Theory," $J$. Acad. Librariansh., vol. 31, no. 1, pp. 46-53, 2005.

[23] M. McCrindle, "New Generations at Work: Attracting, Recruiting Retraining \& Training Generation Y," 2006

[24] A. Lenhart, L. Rainie, and O. Lewis, "Teenage life online: The rise of the instant-message generation and the Internet's impact on frienships and family relationships," 2001. 
[25] A. Carstens and J. Beck, "Get Ready for te Gamer Generation," TechTrends Link. Res. Pract. to Improv. Learn., vol. 49, no. 3, pp. 22-25, 2005.

[26] W. Veen and B. Vrakking, Homo Zappiens: Growing Up in a Digital Age. A\&C Black, 2006.

[27] I. Rowlands, D. Nicholas, P. Williams, P. Huntington, M. Fieldhouse, B. Gunter, R. Withey, H. R. Jamali, T. Dobrowlski, and C. Tenopir, "The Google generation: the information behaviour of the researcher of the future," Aslib Proc. New Inf. Perspect., vol. 60, no. 4, pp. 290-310, 2008.

[28] L. D. Rosen, M. L. Carrier, and N. A. Cheever, Rewired Understanding the iGeneration and the Way They Learn. New York: Palgrave Macmillan, 2010.

[29] L. Johnson, S. Adams Becker, V. Estrada, A. Freeman, P. Kampylis, R. Vuorikari, and Y. Punie, "Horizon Report Europe > 2014 Schools Edition," 2014.

[30] L. Johnson, S. Adams, and M. Cummins, "NMC Horizon Report: 2012 Higher Education Edition,” 2012.

[31] L. Johnson, A. Levine, and R. Smith, "The Horizon Report 2009 Edition," Texas, 2009.

[32] I. Messias and L. Morgado, "Facebook+Moodle: environments to foster students' involvement in distance learning," in ICERI 2014, 2014, pp. 4033-4040.

[33] S. L. Wood, "Technology for Teaching and Learning: Moodle as Tool for Higher Education," Int. J. Teach. Learn. High. Educ., vol. 22, no. 3, pp. 299-307, 2010.

[34] M. Martinho, P. A. Almeida, and J. Teixeira-Dias, "Fostering Students Questioning through Moodle: Does it Work?," Procedia Soc. Behav. Sci., vol. 116, no. iv, pp. 2537-2542, Feb. 2014.

[35] J. DeMers, "The Top 7 Social Media Marketing Trends That Will Dominate 2014 - Forbes," Forbes, 2013. [Online]. Available: http://www.forbes.com/sites/jaysondemers/2013/09/24/the-top-7social-media-marketing-trends-that-will-dominate-2014/. [Accessed: 26-Mar-2014].

[36] C. Madge, J. Meek, J. Wellens, and T. Hooley, "Facebook, social integration and informal learning at university: 'It is more for socialising and talking to friends about work than for actually doing work," Learn. Media Technol., vol. 34, no. 2, pp. 141-155, Jun. 2009 .

[37] M. Nentwich and R. Konig, "Academia Goes Facebook? The Potential of Social Network Sites in the Scholarly Realm," in Opening Science: The Evolving Guide on How the Internet is Changing Research, Collaboration and Scholarly Publishing, SPRINGER Open, 2014, pp. 107-124.

[38] P. B. S. Bassani, "Interpersonal exchanges in discussion forums: A study of learning communities in distance learning settings," Comput. Educ., vol. 56, no. 4, pp. 931-938, May 2011

[39] M. Burke, C. Marlow, and T. Lento, "Social Network Activity and Social Well-Being," in Proceedings of the SIGCHI Conference on Human Factors in Computing Systems, 2010, pp. 1909-1912.

[40] J. P. Mazer, R. E. Murphy, and C. J. Simonds, "I'll See You On "Facebook": The Effects of Computer-Mediated Teacher SelfDisclosure on Student Motivation, Affective Learning, and Classroom Climate," Commun. Educ., vol. 56, no. 3, pp. 1-17, 2007

[41] R. Junco, "The relationship between frequency of Facebook use, participation in Facebook activities, and student engagement," Comput. Educ., vol. 58, no. 1, pp. 162-171, Jan. 2012.

[42] P. Collins, S. Shukla, and D. Redmiles, "Activity Theory and System Design: A View from the Trenches," Comput. Support Coop. Work, vol. 11, no. 1-2, pp. 55-80, Mar. 2002.

[43] Y. Engestrom, LEARNING BY EXPANDING AN ACTIVITYTHEORETICAL APPROACH TO DEVELOPMENTAL RESEARCH. 1987.

[44] D. Schepis, "Social Network Analysis from a Qualitative Perspective," in ANZMAC, 2011, no. Scott 1991.

[45] L. C. Freeman, "The Development of Social Network Analysis with an Emphasis on Recent Events," 2011. [Online]. Available: http://moreno.ss.uci.edu/91.pdf. 